\title{
US seeks fair deal for biologists on synchrotron source access
}

[WASHINGTON] US government agencies are considering how the management and financing of synchrotron radiation sources can best be adapted to cope with the growing number of biologists who want to use them.

A working group of senior officials has been set up by Arthur Bienenstock, associate director of basic research at the White House Office of Science and Technology Policy and former director of the Stanford Synchrotron Radiation Light Source in California. The science office expects the informal group to come up with solutions, which it promises to implement.

The move comes partly in response to complaints from structural biologists that access to the synchrotron sources can take six months or more to arrange. According to officials, the working group will assess likely future demands on the facilities from life scientists, and recommend how to meet needs for instruments, staff and support infrastructure.

Synchrotrons are huge, circular electron beams emitting intense X-rays which researchers use to study crystal structures. Four out of seven of the US facilities are operated by the Department of Energy (DOE) at an annual cost of almost $\$ 180$ million. But structural biologists - most supported by the National Institutes of Health (NIH) - now account for one-third of the users, and the proportion is growing sharply.

Scientists hope that better coordination between the agencies will help to persuade the Congress to relieve pressure on the energy department's budget for operating the synchrotrons by emphasizing their importance to health research. It could also persuade the NIH, whose financial outlook is far healthier than DOE's, to do more to support its researchers at DOE facilities.

The group, led by Marvin Cassman, director of the National Institute of General Medical Sciences at NIH, met for the first

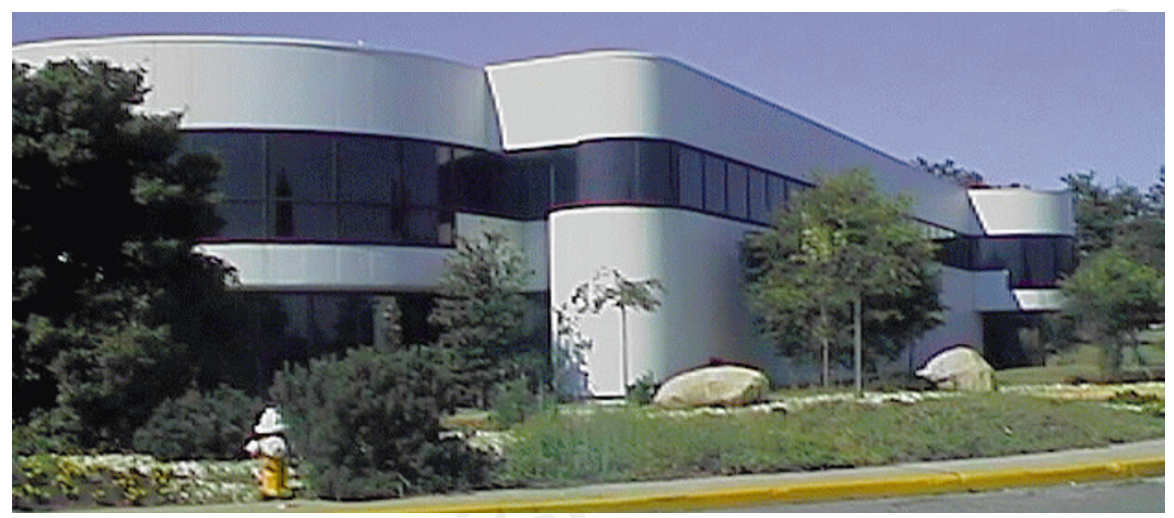

Source of dissatisfaction: Brookhaven's synchrotron source is, like others, in heavy demand.

time three weeks ago. Its other members are Patricia Dehmer, head of basic energy sciences at DOE; Ari Patrinos, head of biological and environmental research at DOE; Judy Vaitukaitis, director of the NIH's National Center for Research Resources; Mary Clutter, associate director for life sciences at the National Science Foundation (NSF); and Jack Rush of the National Institute of Standards and Technology (NIST).

Last week, Cassman asked the DOE's Biological and Environmental Research Advisory Council (BERAC) to summarize available data on the outlook for structural biologists who use DOE synchrotrons. He told the panel: "The people with the money lock up as much beam time as they can, and it gets harder and harder for general users to get on."

The largest DOE synchrotron facilities involved are at Stanford, the Advanced Photon Source at the Argonne National Laboratory in Illinois, and the National Synchrotron Light Source at the Brookhaven National Laboratory, New York. NIST and NSF run smaller facilities.

One issue the working group is expected to tackle is recurrent complaints about the alleged exclusion of individual investigators from beamlines - experimental stations on

\section{Russian reshuffle places Bulgak at helm}

[Moscow] Vladimir Bulgak, formerly a deputy prime minister whose responsibilities included science and technology, was made minister of science and technology in last week's cabinet reshuffle by Russian President Boris Yeltsin.

Unlike Vladimir Fortov, who lost his position in the cabinet as minister of science and technology policy, Bulgak is not a member of the Russian Academy of Sciences. That should reduce the possibility of a conflict of interests in dividing government funding between different scientific organizations.

Bulgak has been an active supporter of reforms to the academy, and has rejected demands from scientific labour unions that such reforms should be postponed (see Nature 388, 315 \& 390, 328; 1997).

He had been considered as a possible candidate to succeed former prime minister Victor Chernomyrdin. the synchrotrons - paid for by wealthy consortia of researchers and corporations.

Each DOE facility was built by the department, and costs it tens of millions of dollars to operate a year. Additional beamlines, which tap X-rays from the synchrotron, are often equipped by private consortia of universities and corporations, who agree to allocate 25 or 30 per cent of the available time on their beamline to other governmentfunded scientists.

But in practice this allocation is not always available. According to Vaitukaitis, some consortia do not provide the support staff that occasional users need. The question of who pays for these staff, for computers and other infrastructure, and even for buildings to house them, is often unresolved.

Such resource questions are compounded by the way the biologists operate, which contrasts with that of the the synchrotrons' traditional user base - physicists and materials scientists. They did experiments that ran for weeks, and took a strong interest in designing, building and supporting the facilities.

The new users have a different approach, says Denis McWhan, associate director of the Brookhaven laboratory. "They don't know how a beamline works, and they want to come in with their crystal and walk out with their data the same day," he says. "We don't have the people to provide the support they need."

Government agencies have started to provide such support: last year, DOE spent $\$ 8$ million on it and the NIH $\$ 6$ million. But an extra $\$ 5.5$ million for support scientists and technicians, and a capital investment of \$12 million, could double the beam time available for structural biologists, according to an unpublished report by Keith Hodgson, professor of chemistry at Stanford University and chairman of BERAC, and Ed Lattman, chairman of biophysics at Johns Hopkins University in Baltimore, Maryland. Colin Macilwain 